\section{Roisin Mullins}

(iD) https://orcid.org/0000-0002-8090-5939

Institute of Management and Health University of Wales Trinity Saint David, UK r.mullins@uwtsd.ac.uk

\section{Monika Eisenbardt}

(iD) https://orcid.org/0000-0002-1133-0537

Faculty of Finance and Insurance University of Economics in Katowice, Poland University of Economics in Katowice, Poland monika.eisenbardt@ue.katowice.pl

\section{Sandra Dettmer}

D https://orcid.org/0000-0002-7120-3986

Faculty of Business and Society

University of South Wales, UK

sandra.dettmer@southwales.ac.uk

\section{Ewa Ziemba}

iD https://orcid.org/0000-0002-1084-7497

Faculty of Finance and Insurance ewa.ziemba@ue.katowice.pl

\title{
Comparing current and future knowledge sharing with enterprises by Poland- and UK-based prosumers
}

Accepted by Editor Wojciech Gamrot | Received: April 21, 2020 | Revised: May 21, 2020 | Accepted: May 22, 2020.

\section{Abstract}

Aim/purpose - The purpose of the paper is to improve understanding of the process activities that Poland-based and UK-based prosumers engage in for current and future knowledge sharing with enterprises. It explores the Poland-based and UK-based prosumer differences and similarities in terms of their engagement with enterprise products and service offerings.

Design/methodology/approach - The reported outcomes result from a survey that yielded 171 prosumers responses from the United Kingdom and 783 from Poland. The APQC framework is used as a means to establish the product versus service activities that appear to influence prosumers most in their knowledge sharing.

Findings - The findings show that Poland-based prosumers currently share knowledge marginally more than their counterparts in the UK. However, Poland based prosumers are more willing, in fact twice as likely, to share knowledge in the future in relation to product offerings including (P3) materials from which products were made, followed closely by (P6) ease and intuitiveness of product use, (P4) designing package or graphic elements of the product and (S4) establishing new channels of sale.

Cite as: Mullins, R., Dettmer, S., Eisenbardt, M., \& Ziemba, E. (2020). Comparing Poland and UK prosumers' current and future knowledge sharing with enterprises. Journal of Economics \& Management, 4l(3), 47-68. https://doi.org/10.22367/ jem.2020.41.03 
Research implications/limitations - In particular, the results reveal that both the Poland-based and UK-based prosumers want to engage with enterprises in sharing knowledge related to the ordering process, handling complaints and customer services.

Originality/value/contribution - This finding is relevant to any enterprises that may like to engage prosumers in providing feedback about their specific product and service offerings.

Keywords: consumer knowledge, prosumer, knowledge sharing, Poland, UK.

JEL Classification: D82, D83, M21, O31, O33.

\section{Introduction}

Technology developments such as widely used Internet-based technologies improve customer's access to enterprises giving them a voice and with that a new level of control (O'Brien, 2011), creating new relationship challenges with the enterprise. These social media platforms are included as part of the enterprises marketing and digital business strategies whereby they are considered vital tools for capturing customers reactions, satisfaction levels, and stimulate purchase power through the ratings and responses gleaned from customer reviews, blogs, online forms, and general chat groups. It is these conversations that become the ingredients to gauge customers' acceptance levels and their perceived value of the product and service offerings (Osterwalder \& Pigneur, 2002). The Internet technologies provide the enterprise with opportunities to refocus and reaffirm the value offer and endorse the customer's feedback which creates the novel opportunity to execute the strategy placing the value proposition for the product and service at the centre of the business model (Osterwalder \& Pigneur, 2013).

As enterprises deliberate over emerging sustainability actions and addressing scarcity or resources in product and service offering, alongside the growing concerns of customers for enterprises to show, they are exploiting and fulfilling circular economy undertakings, such as process changes, tools, standard, policies and resource changes. The enterprises that adapt their systems and respond to customer demands and global market trends that concern ethical products (Martínez-Cañas, Ruiz-Palomino, Linuesa-Langreo, \& Blázquez-Resino, 2016) through integrated systems will have a greater capacity to utilise customer interaction more effectively. This notion of external customer's closer engagement in the customer facing activities of the enterprise is often referred to as value co-creation and has been described by authors as a significant value creation process (Lusch \& Vargo, 2006a; Payne et al., 2008). The practice of creating 
value through co-creating and co-existing is deemed a central action whereby enterprises encourage knowledge sharing of product and services (Ritzer \& Jurgenson, 2010; Tapscott \& Williams, 2006).

Our study is largely pursuing how the inclusion of technology, especially web 2.0 technology, in digital business enterprise strategies informs the value offer as well as nurtures the customer relationship dynamic. It is therefore reasonable to use the terms prosumer rather than co-creator. The term prosumer is directly connected with a prosumption term which means the process in which prosumers actively share knowledge with enterprises or other prosumers (Bylok, 2013; Fine, Gironda, \& Petrescu, 2017; Hernández-Serrano, Renés-Arellano, Graham, \& Greenhill, 2017; Rayna \& Striukova, 2016; Ritzer \& Jurgenson, 2010; Tapscott \& Williams, 2006; Xie, Bagozzi, \& Troye, 2008). Prosumers' activities are also referred to as the activities undertaken to produce new products and services of value for enterprises as well as for themselves (Ziemba, Eisenbardt, Mullins, \& Grabara, 2018).

The term prosumer, illustrated by Toffler (1980), explains how the duality of the customer and enterprise relationship complement the innovations and explicit knowledge sharing potential which is essential in the competitive marketplace (Cui \& Wu, 2015; Geri, Gafni, \& Bengov, 2017; Taherparvar, Esmaeilpour, \& Dostar, 2014). However, there are complexities in managing and executing the online communication relationship, and while the focus on interaction with prosumers is expected to be central to the marketing plan in recognizing them as valuable strategic assets (Planells, 2015; Ziemba \& Mullins, 2016), few enterprises manage this to see its wider potential not just in terms of loyalty and branding. Yet, where the consumer becomes a recognised actor, external to the enterprise, and is joining activities in the value chain, it becomes more acceptable for enterprise to respond to the consumer needs and value development (Aghamirian, Dorri, \& Aghamirian, 2013; Brabham, 2012; Song \& Kang, 2016; Tsai, Tsai, Li, \& Lin, 2012; Tseng, 2016). It is considered that prosumers' knowledge is largely unexplored as enterprises do not have the means to analyse and ultimately gain a clear and precise stratification of the customer groups (Ziemba, Eisenbardt, \& Mullins, 2017). It is only through this stratification process of the prosumer groups that the enterprises will be led to the greater personalisation of products and service offers. Prosumers' participation in the process of co-creation or even co-production of services (Ritzer \& Jurgenson, 2010; Tapscott \& Williams, 2006) plays a considerable role in the whole service life cycle. Consequently, prosumers' knowledge can be embedded 
into the business process stages which may lead to the development of new products, upgrading of existing products or improvements in the products, service developments, upgrading and improvement of existing services (Ziemba \& Eisenbardt, 2015b; Ziemba et al., 2018). The business process stages that are recognized as customer-facing are reported in the APQC Process Classification Framework (APQC, 2018), which is considered appropriate for a conceptual framework of prosumer participation in business processes. In their paper, the focus is on four customer-facing operational processes in which prosumers' knowledge can be notably captured and used. These business processes (BP) are: Process 2.0 Develop and Manage Products and Services; Process 3.0 Market and Sell Products and Services; Process 4.0 Deliver Products and Services; and Process 5.0 Manage Customer Service. Table 1 below indicates the types of product and services development knowledge that prosumers can share with enterprises.

This modified AQPC process model details the items associated with each process as part of product and service developments. As such, the survey questions were designed to determine the prosumer knowledge associated with each of the process stages.

Therefore, this paper aims at answering two research questions of 1) what kind of knowledge about products do Poland-based and UK-based prosumers share and would like to share? 2) what kind of knowledge about services do Poland-based and UK-based prosumers share and would like to share? Consequently, the objectives of the paper are twofold. Firstly, the analysis of business processes in which prosumers can share knowledge, which in turn lead us to indicating the kinds of knowledge which prosumers share about products and services. Secondly, a comparative analysis is performed to determine what knowledge prosumers share and would like to share.

The paper is organised as follows: the research questions followed by the research methodology; then results, analysis, and discussion are provided; and the paper concludes with a summary, limitations, and avenues for future research.

\section{Prosumers' engagement in business processes}

Prosumers' knowledge is a determinant in the design of activities associated with business process stages. There are many models and classifications of business processes in the literature, for example, Porter's classification (Porter, 1985) and congeneric APQC (American Productivity and Quality Center) Pro- 
cess Classification Framework (PCF) (APQC, 2018). In using the APQC PCF, Ziemba \& Eisenbardt (2015b) proposed a conceptual framework of prosumer engagement for creating business process innovations. The choice of the PCF was justified by the fact that this framework is a taxonomy of cross-functional business processes intended to allow for the objective comparison of organizational performance within and among organizations. The PCF sets an open standard to encourage improvement through process management and benchmarking, irrespective of industry, its size, or location (APQC, 2018). The proposed framework embraces four operational processes in which prosumers' engagement can be notably used for creating innovations. They are the following: (1) developing and managing products; (2) marketing and selling products and services; (3) delivering products and services, and (4) managing customer service. For each of these processes, various types of prosumer engagement have been indicated. Based on further research (Ziemba et al., 2018), it was possible to modify the framework. In doing so, some types of prosumer engagement have been combined while others have been removed from this framework. The modified framework used in this research is presented in Table 1.

Table 1. The conceptual framework of prosumers' engagement in business processes (Numbering identification of processes is associated with APQC PCF)

\begin{tabular}{|l|c|l|}
\hline Operational Business Processes & Item & \multicolumn{1}{|c|}{ Kind of knowledge } \\
\hline \multirow{5}{*}{ BP2.0 Develop and Manage Products } & P1 & New product design \\
\cline { 2 - 3 } & P2 & Materials from which the product was made \\
\cline { 2 - 3 } & P3 & Package or graphic elements of the product \\
\cline { 2 - 3 } & P4 & Product functionality \\
\cline { 2 - 3 } & P5 & Reliability and durability of the product \\
\cline { 2 - 3 } & P6 & Ease and intuitiveness of product use \\
\cline { 2 - 3 } & P7 & Product performance \\
\hline \multirow{5}{*}{ BP3.0 Market and Sell Services } & S1 & Advertising/marketing \\
\cline { 2 - 3 } & S2 & Pricing strategy \\
\cline { 2 - 3 } & S3 & Promotions, discounts, loans \\
\hline BP4.0 Deliver Services & S4 & Service availability and distribution channels \\
\cline { 2 - 3 } & S5 & Ordering process \\
\hline BP5.0 Manage Customer Service & S6 & Complaint handling and warranty services \\
\cline { 2 - 3 } & S7 & Customer service \\
\hline
\end{tabular}

Source: APQC (2018); Ziemba \& Eisenbardt (2015b); Ziemba et al. (2018).

The engagement of prosumers presented in Table 1 becomes quite significant for the business at each stage of the innovation process. For instance, prosumers can co-create a concept of a new product (idea generation), prosum- 
ers can co-design new products (development), and prosumers can co-price and co-distribute the new products (commercialisation). In this respect the framework provides good opportunity to explore deep prosumer engagement activities.

\section{The methodology of the research}

\subsection{Research questions and hypotheses}

Existing research studies show that prosumers can share knowledge about products and services and at the same time have an impact on development of products and services (Ziemba \& Eisenbardt, 2015ab), but the results were from Poland-based prosumers only. The extensive review of the literature did not uncover any detailed studies concerning business processes development, especially services development, and prosumers' knowledge sharing. What is more, the scope of the literature does not focus on different countries comparisons in relation to the service process stages. The research among Poland-based and UK-based prosumers aims at improving our understanding of prosumers' knowledge sharing for product and service development.

The aim of the study is to compare which kinds of knowledge the Poland-based and UK-based prosumers share and which kinds of knowledge would they like to share about enterprise products and service offers?

The study tests whether there are statistically significant differences between knowledge about services that Poland-based and UK-based prosumers share, and similarly whether there are statistically significant differences between knowledge about services that Poland-based and UK-based prosumers would like to share. In practical terms, enterprises gain new insight from these findings with specific reference to Poland-based and UK-based prosumers knowledge sharing about services and products what may help them to make decisions about which projects and activities they can engage with prosumers for future knowledge sharing. The study was designed around eight main questions:

RQ1: What knowledge about products do Poland-based prosumers share?

RQ2: What knowledge about products do UK-based prosumers share?

RQ3: What knowledge about services do Poland-based prosumers share?

RQ4: What knowledge about services do UK-based prosumers share?

RQ5: What knowledge about products would Poland-based prosumers like to share? 
RQ6: What knowledge about products would UK-based prosumers like to share?

RQ7: What knowledge about services would Poland-based prosumers like to share?

RQ8: What knowledge about services would UK-based prosumers like to share?

Table 2 also indicates the knowledge areas with those product and service question items associated with the process stages.

Table 2. The process framework indicating prosumer knowledge areas addressed

\begin{tabular}{|l|l|c|}
\hline \multicolumn{1}{|c|}{ Operational Business Processes } & \multicolumn{1}{|c|}{ Product and Service Items } & Knowledge Areas \\
\hline BP2.0 Develop and Manage Products & P1-P7 & Products offer \\
\hline BP3.0 Market and Sell Services & S1-S3 & \multirow{2}{*}{ Services offer } \\
\hline BP4.0 Deliver Services & S4-S5 & \\
\hline BP5.0 Manage Customer Service & S6-S7 & \\
\hline
\end{tabular}

Table 2 presents the framework of operational business processes and product and service items for each of business process. That approach enabled us to compare each stage of the process and post four hypotheses which are as follow: H1: There is a statistically significant difference between Poland-based and UK-based prosumers engagement in knowledge sharing in BP2 combined activities. H2: There is a statistically significant difference between Poland-based and UK-based prosumers engagement in knowledge sharing in BP3, 4 and 5 combined activities.

H3: There is a statistically significant difference between Poland-based and UK-based prosumers future engagement in knowledge sharing in BP2 combined activities.

H4: There is a statistically significant difference between Poland-based and UK-based prosumers future engagement in knowledge sharing in BP3, 4 and 5 combined activities.

\subsection{Research procedure}

Research methods included a critical review of the literature, logical deduction, case studies, a survey questionnaire, and statistical analysis. The research process included the following steps: 
LITERATURE: A critical review of existing studies related to 'prosumption,' 'prosumer,' 'customer,' 'consumer,' 'knowledge sharing,' 'business processes,' and 'services' enabled examination of prosumers knowledge sharing to develop and manage services. The review embraces four bibliographic data-bases: Ebsco, ProQuest, Emerald Management, and ISI Web of Knowledge. In addition, some journals and Web materials dedicated to research on 'consumption' and 'prosumption' were also explored.

CASE STUDIES: Case studies of prosumers' knowledge sharing indicated that prosumers can share their knowledge and, at the same time, they can develop and manage services (Ziemba \& Eisenbardt, 2015b). Based on the analysis of literature, as well as the analysis of the abovementioned case studies, the specific kinds of knowledge which they can share about services were proposed.

PILOT: An initial pilot questionnaire was designed in Polish and translated into English for the UK participants. The English translation was undertaken in Poland and the questionnaire was evaluated and pretested with colleagues and a sample of respondents in the UK University to determine suitability and appropriateness for the survey. The questionnaire was divided into two parts. After a few demographics questions all participants were obliged to answer the question: Have you ever assessed or commented on products or companies, proposed products improvements to the companies or designed new products? This question enabled the division of respondents into consumers (not active in this matter) and prosumers (active ones). The questionnaire contained questions concerning specified kinds of knowledge that prosumers can share. The questions were: (1) Please indicate, what were your assessments or comments on services or proposals for developments of services? (2) If you could in a free and unlimited way share your knowledge about services, propose ideas of service developments or ideas for the design of new services - please indicate what would your proposals be concerned with? The pilot questionnaire was directed only to prosumers. The final questionnaire was directed to both - prosumers and consumers. The pilot data were not included with the final dataset for analysis. The kinds of knowledge about services were listed for these questions (Table 2). For each listed kind of knowledge the respondents could choose one of five responses, according to a 5-point Likert scale: (1) definitely no, (2) rather no, (3) neither yes nor no, (4) rather yes, (5) definitely yes. In November 2014 a more in-depth pilot survey was conducted in Poland. The purpose was substantive and methodological scrutiny of the questionnaire. To conduct reliability analysis, Cronbach's coefficient alpha was used. For all the analysed items the Cronbach's alpha was 0.785 . According to Hinton, Brownlow, McMurray, \& Cozens (2004), it can be concluded that the scale had acceptable to good reliability, and it could be 
used in the research process. Moreover, substantive scrutiny of the questionnaire enabled to perform minor changes to improve the quality of the questionnaire.

CAWI: Applying the Computer-Assisted Web Interview (CAWI) method and employing the Poland platform Ankietka.pl, and the UK platform Bristol Online Survey (BOS), hosted at the University of Bristol, the questionnaire was uploaded to the website. Data collection took place between the end of December 2014 and March 2015 in Poland, and between February and April 2016 in the United Kingdom.

SAMPLE: In Poland, the designed sample size was 2,500 people, comprising people of different age, gender, and ICT skills. In the UK, the online survey letter and URL was initially posted to 1,000 individuals comprising people of different age, gender, and ICT skills. Using online tools permits contact with an accessible audience as the survey appears on search engine lists due to metatags and appropriate placing of keywords. After screening the responses and excluding outliers, there was a final research sample of 783 usable, correct and complete questionnaires from Poland and 171 from the United Kingdom. The data were stored in Microsoft Excel format. The demographic analysis of the research sample is presented in Table 3. The demographics provide a description of the characteristics of individuals who engage in the prosumer process.

Table 3. Demographic analysis of the research sample

\begin{tabular}{|c|c|c|c|c|}
\hline \multirow[b]{2}{*}{ Demographic profile } & \multicolumn{2}{|c|}{ Poland } & \multicolumn{2}{|c|}{ United Kingdom } \\
\hline & $\begin{array}{c}\text { number } \\
\text { of respondents }\end{array}$ & percentage & $\begin{array}{c}\text { number } \\
\text { of respondents }\end{array}$ & percentage \\
\hline \multicolumn{5}{|l|}{ Gender } \\
\hline female & 599 & $76.5 \%$ & 98 & $57.3 \%$ \\
\hline male & 184 & $23.5 \%$ & 73 & $42.7 \%$ \\
\hline \multicolumn{5}{|l|}{ Age } \\
\hline builders generation: over 65 years old & 14 & $1.8 \%$ & 8 & $4.68 \%$ \\
\hline baby-boomers generation: 51-65 years old & 35 & $4.5 \%$ & 25 & $14.62 \%$ \\
\hline$X$ generation: $36-50$ years old & 108 & $13.8 \%$ & 67 & $39.18 \%$ \\
\hline Y generation: $21-35$ years old & 369 & $47.1 \%$ & 68 & $39.77 \%$ \\
\hline Z generation: less than 21 years old & 257 & $32.8 \%$ & 3 & $1.75 \%$ \\
\hline \multicolumn{5}{|l|}{ Level of education } \\
\hline higher education & 217 & $27.7 \%$ & 89 & $52.05 \%$ \\
\hline secondary education & 559 & $71.4 \%$ & 75 & $43.86 \%$ \\
\hline less than secondary education & 7 & $0.9 \%$ & 7 & $4.09 \%$ \\
\hline \multicolumn{5}{|l|}{ Place of residence } \\
\hline city with a population of more than 100,000 & 419 & $53.5 \%$ & 96 & $56.14 \%$ \\
\hline city with a population of less than 100,000 & 244 & $31.2 \%$ & 53 & $30.99 \%$ \\
\hline rural area & 120 & $15.3 \%$ & 22 & $12.87 \%$ \\
\hline
\end{tabular}


The demographics for the Poland-based and UK-based respondents vary in terms of age. Whereas $79.9 \%$ of Poland-based respondents fall into $\mathrm{Y}$ and $\mathrm{Z}$ generation categories, only $41.52 \%$ of UK-based respondents are younger than 35 years of age. The level of education of the UK-based respondents is at a higher level than the Poland-based respondents. There are no main differences in the respondents' place of residence.

RELIABILITY: As the process of collecting data was completed, the reliability was calculated. The Cronbach's Alpha coefficient with all seven items for BP2 confirmed a high internal consistency (0.86). Furthermore, the Cronbach's alpha coefficient with all seven items for BP3, BP4 and BP5 confirmed (0.79) reliable variance which is deemed an 'acceptable to good' reliability for internal consistency because it leaves $21 \%$ error variance. In addition, it was determined that the removal of some items would not lead to the significant improvement of internal consistency among items on the scale. Therefore, it was decided that for further analyses all seven items would be used.

STATISTICAL ANALYSES: In order to answer the research questions and test the research hypotheses, the statistical analysis was employed. Firstly, the descriptive analysis was employed to describe kinds of knowledge about products that prosumers share and would like to share. The following statistics were calculated: mean, median (MDN), mode, standard deviation (SD), coefficient of variation (CV), and skewness (SK). Secondly, treating both samples as sequences of independent and identically distributed random variables, the Mann-Whitney U test was applied in order to identify differences between Poland-based and UK-based prosumers about whether they share and would like to share knowledge about products and services. This test was selected because it does not make any assumptions related to the distribution, and it is used to test whether two independent samples of observations are drawn from the same or identical distribution. The statistical analysis was made using MS Excel and SPSS (ver.24) software.

\section{Research findings}

In order to answer RQ1-RQ4, a detailed analysis concerning knowledge about products and services that Poland and UK based prosumers share was completed. The results are presented in Table 4. 
Table 4. Knowledge about products and services that Poland-based and UK-based prosumers share

\begin{tabular}{|c|c|c|c|c|c|c|c|c|c|c|c|c|}
\hline \multirow{2}{*}{ Item } & \multicolumn{5}{|c|}{ Poland-based prosumers } & \multicolumn{5}{c|}{ UK-based prosumers } \\
\cline { 2 - 14 } & Mean & MDN & Mode & SDV & CV & SK & Mean & MDN & Mode & SDV & CV & SK \\
\hline P1 & 2.72 & 3 & 4 & 1.29 & 0.48 & -0.98 & 2.68 & 2 & 2 & 1.07 & 0.40 & 0.64 \\
\hline P2 & 2.94 & 3 & 4 & 1.24 & 0.42 & -0.85 & 2.76 & 2 & 2 & 1.09 & 0.40 & 0.70 \\
\hline P3 & 2.87 & 3 & 4 & 1.27 & 0.44 & -0.88 & 2.37 & 2 & 2 & 0.92 & 0.39 & 0.40 \\
\hline P4 & 3.76 & 4 & 4 & 1.11 & 0.30 & -0.21 & 2.93 & 2 & 2 & 1.17 & 0.40 & 0.80 \\
\hline P5 & 3.58 & 4 & 4 & 1.22 & 0.34 & -0.34 & 2.97 & 2.5 & 2 & 1.14 & 0.38 & 0.85 \\
\hline P6 & 3.67 & 4 & 4 & 1.18 & 0.32 & -0.28 & 2.96 & 2 & 2 & 1.17 & 0.40 & 0.82 \\
\hline P7 & 3.46 & 4 & 4 & 1.26 & 0.36 & -0.42 & 3.12 & 4 & 2 & 1.14 & 0.37 & 0.98 \\
\hline S1 & 2.58 & 2 & 2 & 1.41 & 0.54 & 0.34 & 2.09 & 2 & 2 & 0.80 & 0.40 & 1.89 \\
\hline S2 & 3.01 & 3 & 4 & 1.38 & 0.46 & -0.18 & 2.55 & 2 & 2 & 1.15 & 0.47 & 0.57 \\
\hline S3 & 1.77 & 1 & 1 & 0.99 & 0.56 & 1.31 & 2.29 & 2 & 2 & 1.11 & 0.58 & 0.80 \\
\hline S4 & 3.01 & 3 & 4 & 1.30 & 0.43 & -0.17 & 2.45 & 2 & 2 & 1.08 & 0.50 & 0.54 \\
\hline S5 & 3.45 & 4 & 4 & 1.31 & 0.38 & -0.57 & 3.29 & 4 & 4 & 1.26 & 0.41 & -0.37 \\
\hline S6 & 3.20 & 4 & 4 & 1.36 & 0.42 & -0.31 & 3.26 & 4 & 4 & 1.25 & 0.40 & -0.26 \\
\hline S7 & 3.62 & 4 & 4 & 1.27 & 0.35 & -0.75 & 3.61 & 4 & 4 & 1.19 & 0.35 & -0.94 \\
\hline
\end{tabular}

Note: Abbreviations used: MDN - median, SD - standard deviation, CV - coefficient of variation, and SK - skewness.

The results presented in Table 4 show that Poland-based prosumers mainly share their knowledge about product functionality ( $\mathrm{P} 4$ mean 3.76), ease and intuitiveness of product use (P6, mean 3.67), improving customer service (mean $3.62)$, reliability and durability of the product ( $\mathrm{P} 5$, mean 3.58), product performance (P7, mean 3.46), improving ordering process (S5, mean 3.45), improving handling complaints and warranty services (S6, mean 3.20), product pricing strategy and establishing new channels of sale (S2, Mean 3.01) materials used in product ( $\mathrm{P} 2$, mean 2.94), Package or graphic elements of the product (P3, mean 2.87), product design ( $\mathrm{P} 1$, mean 2.72), advertising campaigns ( $\mathrm{S} 1$, mean 2.58) and product loans strategy ( $\mathrm{S} 3$, mean 1.77). Of the top five items ranked in ascending order, the top four items were associated with developing and managing product offerings, BP2. The only service offering in the top five items appears in the third place and relates to BP5.

On the other hand, the UK-based prosumers favour sharing knowledge about service offerings above product offerings. The results indicate that consumer service (S7, mean 3.61) rates highest followed by ordering process (S5, mean 3.29), handling complaints and warranty services (S6, mean 3.26), product performance (P7, mean 3.12), reliability and durability of the product (P5, mean 2.97), ease and intuitiveness of product (P6, mean 2.96), product functionality ( $\mathrm{P} 4$, mean 2.93), materials used in product ( $\mathrm{P} 2$, mean 2.76$)$, product design ( $\mathrm{P} 1$, mean 2.68), product pricing ( $\mathrm{S} 2$, mean 2.55), new channels of sale ( $\mathrm{S} 4$, mean 
2.45), package or graphic elements of the product ( $\mathrm{P} 3$, mean 2.37), product loans strategy (S3, mean 2.29) and lastly advertising campaigns (S1, mean 2.09). Of the top five items ranked in ascending order, the top three items were associated with service offerings in the stages BP5 and BP4 followed by developing and managing product offerings, BP2. This is the opposite result to Poland-based prosumers' preferences where UK-based prosumers place service offerings in higher regard than product offerings.

The means of current engagement in individual knowledge sharing processes are presented in Figure 1.

Figure 1. Poland- versus UK-based prosumers engagement in knowledge sharing

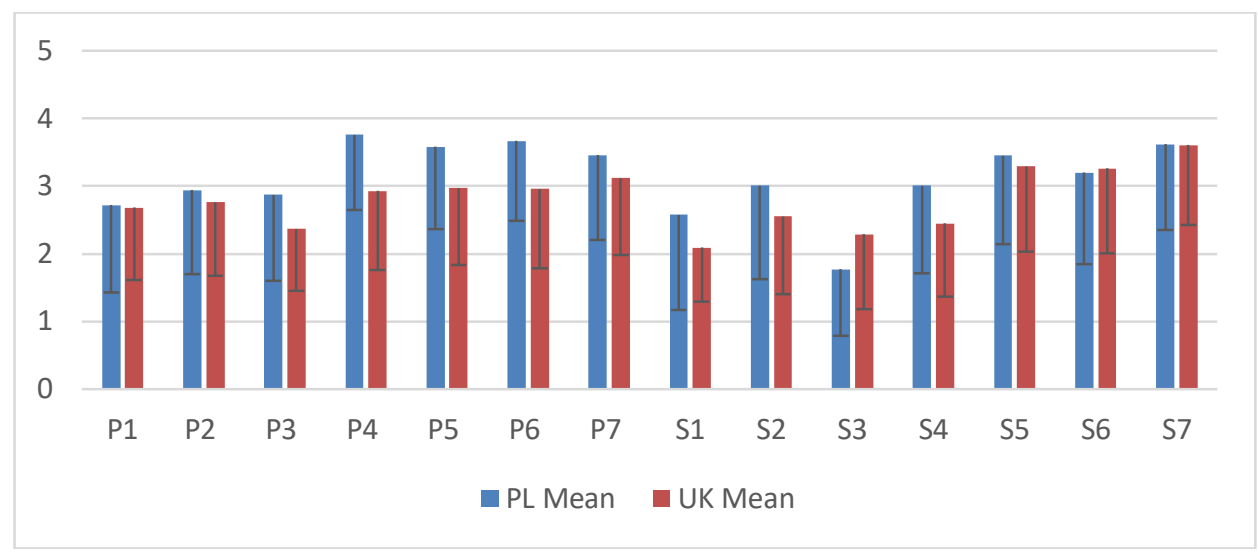

Both Poland-based and UK-based prosumers view service offerings, S1 and S3 with least interest and it is unsurprising as these relate to advertising and loans service design that did not rely heavily on consumer's views and input in the past.

The general analysis of the results shows that Poland-based prosumers share knowledge more widely than UK-based ones.

In order to answer the questions RQ5-RQ8, a detailed analysis concerning knowledge about products and services that Poland-based and UK-based prosumers would like to share was completed. The results are presented in Table 5. 
Table 5. Knowledge about products and services that Poland-based and UK-based prosumers would like to share

\begin{tabular}{|c|c|c|c|c|c|c|c|c|c|c|c|c|}
\hline \multirow{2}{*}{ Item } & \multicolumn{9}{|c|}{ Poland-based prosumers } & \multicolumn{5}{c|}{ UK-based prosumers } \\
\cline { 2 - 14 } & Mean & MDN & Mode & SDV & CV & SK & Mean & MDN & Mode & SDV & CV & SK \\
\hline P1 & 3.62 & 4 & 4 & 1.15 & 0.32 & -0.33 & 2.93 & 2 & 2 & 1.36 & 0.40 & 0.80 \\
\hline P2 & 3.71 & 4 & 4 & 1.09 & 0.29 & -0.27 & 2.98 & 2 & 2 & 1.30 & 0.38 & 0.86 \\
\hline P3 & 3.38 & 4 & 4 & 1.15 & 0.34 & -0.54 & 2.33 & 2 & 2 & 0.88 & 0.40 & 0.35 \\
\hline P4 & 4.16 & 4 & 4 & 0.92 & 0.22 & 0.18 & 2.97 & 2 & 2 & 1.45 & 0.41 & 0.81 \\
\hline P5 & 4.04 & 4 & 5 & 1.07 & 0.26 & -0.90 & 3.12 & 4 & 4 & 1.40 & 0.38 & -0.75 \\
\hline P6 & 4.23 & 4 & 5 & 0.86 & 0.20 & -0.89 & 2.93 & 2 & 2 & 1.32 & 0.39 & 0.81 \\
\hline P7 & 3.99 & 4 & 5 & 1.03 & 0.26 & -0.98 & 3.04 & 3 & 2 & 1.42 & 0.39 & 0.87 \\
\hline S1 & 2.84 & 3 & 2 & 1.25 & 0.44 & 0.16 & 2.18 & 2 & 2 & 0.94 & 0.43 & 1.54 \\
\hline S2 & 3.52 & 4 & 4 & 1.17 & 0.33 & -0.57 & 2.63 & 2 & 2 & 1.22 & 0.46 & 0.26 \\
\hline S3 & 2.46 & 2 & 2 & 1.09 & 0.44 & 0.42 & 2.45 & 2 & 2 & 1.18 & 0.48 & 0.44 \\
\hline S4 & 3.52 & 4 & 4 & 1.14 & 0.32 & -0.54 & 2.58 & 2 & 2 & 1.17 & 0.47 & 0.39 \\
\hline S5 & 3.45 & 4 & 4 & 1.23 & 0.36 & -0.40 & 3.33 & 4 & 4 & 1.29 & 0.39 & -0.63 \\
\hline S6 & 3.48 & 4 & 4 & 1.24 & 0.36 & -0.46 & 3.26 & 4 & 4 & 1.19 & 0.36 & -0.35 \\
\hline S7 & 3.66 & 4 & 4 & 1.17 & 0.32 & -0.65 & 3.30 & 4 & 4 & 1.17 & 0.35 & -0.42 \\
\hline
\end{tabular}

Note: Abbreviations used: MDN - median, SD - standard deviation, CV - coefficient of variation, and SK - skewness.

It was found that Poland-based prosumers would mainly share their knowledge about items ease and intuitiveness of product (P6, mean 4.23), product functionality ( $\mathrm{P} 4$, mean 4.16), reliability and durability of the product (P5, mean 4.04), product performance (P7, mean 3.99), materials design (S2, mean 3.71), improving consumer service (S7, mean 3.66), product design (P1, mean 3.62 ), product pricing strategy (S2, mean 3.52), handling complaints and warranty services (S6, mean 3.48), improving ordering process (S5, mean 3.45), package or graphic elements of the product (P3, mean 3.38), advertising campaigns (S1, mean 2.84) and lastly loans strategy (S3, mean 2.46). The Poland-based prosumers' top five items relate to developing and managing product offerings, stage BP2, with the sixth item being improving customer service offerings BP5.

They are more likely to expect to share knowledge with enterprises in the future in these items than they currently share at the present time. The future concerns are with the early design stages where prosumer input can affect the complete product development and the prosumers felt more strongly about engaging in these areas in the future possibly as customers are concerned about ecology and environment, and scarcity of products.

The means of future engagement in individual knowledge sharing processes are presented in Figure 2. 
Figure 2. Poland- versus UK-based prosumers engagement in future knowledge sharing

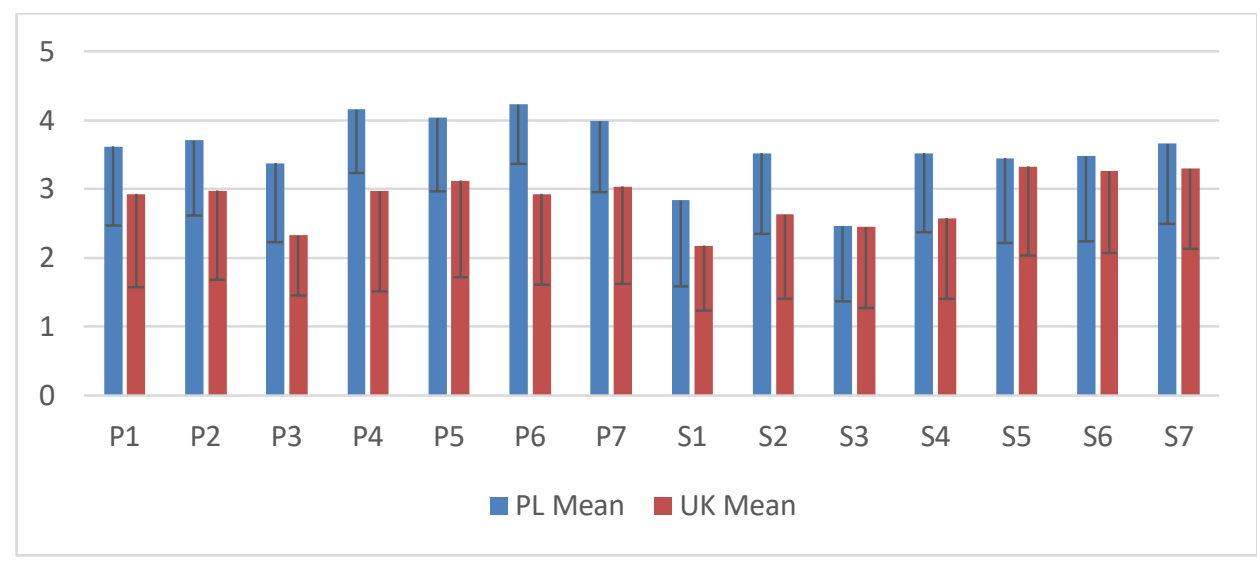

On the other hand, the results clearly show that, in general, UK-based prosumers are reluctant to share certain kinds of knowledge in the future. The highest rated item relates to improving the ordering process (S5, mean 3.33), followed closely by improving consumer services (S7, mean 3.30), handling complaints and warranty services (S6, mean 3.26), reliability and durability of the product ( $\mathrm{P} 5$, mean 3.12), product performance (P7, mean 3.04), materials design ( $\mathrm{P} 2$, mean 2.98), product functionality ( $\mathrm{P} 4$, mean 2.97), product design and ease and intuitiveness of product use ( $\mathrm{P} 1$ and $\mathrm{P} 6$, mean 2.93), product pricing strategy (S2, mean 2.63), new channels of sale (S4, mean 2.58), product loans strategy ( $\mathrm{S} 3$, mean 2.45), package or graphic elements of the product ( $\mathrm{P} 3$, mean 2.33) and lastly advertising campaigns (S1, mean 2.18).

The top three items are associated with service offerings in the stages BP5 and BP4 followed by developing and managing product offerings, BP2. This is the opposite result to Poland-based prosumers' preferences where UK-based prosumers place service offerings in higher regard than product offerings. The result is similar in the future to the prosumers current view of how they share knowledge with enterprises.

\section{Discussion of research findings}

Following the previously presented results, the main findings are summarised in the form of Tables 6 and 7. The results from the Mann-Whitney U test confirm statistically significant differences between Poland-based and UK-based prosumers in terms of their current engagement with organisations in nine out of 
the 14 business processes. The p-value is lower than 0.05 (the significance level for the study is 0.05 ) for all business processes within BP2 which are related to the specific product offering. Thus, H1 is fully supported

However, the results for BP3, BP4 and BP5 are more varied and suggest significant differences between Poland-based and UK-based prosumers in the processes $\mathrm{S} 1$ to $\mathrm{S} 4$, i.e. there are significant differences in the current prosumer activities in terms of advertising (S1), pricing strategy (S2), promotions (S3) and service availability (S4) whereas no significant differences can be reported for ordering processes (S5), complaint handling (S6) and customer services (S7). It can therefore be summarised that $\mathrm{H} 2$ was partially supported by the results.

Table 6. The Mann-Whitney U test results for exploring the differences between Poland- and UK-based prosumers' current engagement in knowledge sharing

\begin{tabular}{|c|c|}
\hline \multicolumn{2}{|c|}{ Engagement in knowledge sharing (currently share) } \\
\hline P1 & 0.000 \\
\hline P2 & 0.000 \\
\hline P3 & 0.000 \\
\hline P4 & 0.000 \\
\hline P5 & 0.000 \\
\hline P6 & 0.000 \\
\hline P7 & 0.000 \\
\hline S1 & 0.021 \\
\hline S2 & 0.011 \\
\hline S3 4 & 0.000 \\
\hline S5 & 0.001 \\
\hline S6 & 0.306 \\
\hline S7 & 0.744 \\
\hline
\end{tabular}

Poland-based prosumers show a higher engagement in all business processes related to BP2 and the differences are significant. The differences are especially pronounced in terms of product functionality (P4), ease and intuitiveness of product use (P6) and reliability and durability of the product. This suggest that Poland-based prosumers have a much higher interest in engaging in the actual processes related to products compared to UK-based prosumers. This finding could be explained by the fact that the rise of consumerism and the empowerment of Poland-based consumers is still perceived as a new development in the Poland economy, and they take a larger interest in participating as active consumers compared to their UK-based counterparts (Mazurek \& Hilton, 2007). Furthermore, the result could also show the different priorities of consumers in 
the different countries. Whereas Poland-based consumers are more concerned to satisfy a need and provide feedback in terms of the fundamental business processes, such as (P4) and (P6), UK-based consumers identify differentiation opportunities at a different level which is more linked to the service provision.

The higher level of engagement from Poland-based prosumers also applies to all but one activity in BP3, BP4 and BP5, but the differences are not significant for S5, S6 and S7. UK-based prosumers exceed Poland-based prosumers in the mean for S6, complaint handling and warranty services. Prosumers from both countries generally show a high engagement in the business processes linked to ordering processes, complaint handling and warranty services and customer service. This result can be explained by the nature of these services as they are at the interface between consumers and organisations and they have already engaged in a two-way communication process. Taking the interpretation of this finding further it is possible to argue that organisations could benefit more from the external consumer input and knowledge by softening or breaking up the boundaries of the organisation. In the literature, the benefits of open business models in terms of addressing increasing development costs and shorter product life cycles have been linked to external knowledge input from other organisations (Chesbrough, 2007).

The Mann-Whitney $U$ test results for future knowledge sharing between Poland-based and UK-based prosumers are presented in Table 7 and are very similar to the previous comparison of current prosumer engagement, i.e. the $\mathrm{p}$ values for $\mathrm{P} 1$ to $\mathrm{P} 7$ are significant at 0.05 level and suggest significant differences between the two prosumer groups for all processes within BP2. Thus, $\mathrm{H} 3$ can be fully supported. By looking more closely at the individual results, it can be observed that the differences in mean values between Poland-based and UK-based prosumers are larger for future engagement compared to current prosumer activity. For instance, Poland-based prosumers are almost twice as likely to engage in knowledge sharing about packing or graphic elements of the product $(\mathrm{P} 3)$ then UK-based prosumers and more than 1.5 times more willing to engage in knowledge sharing for product functionality (P4) and ease and intuitiveness of product use (P6). Differences of the same magnitude can be found for advertising and marketing (S1), pricing strategy (S2) and service availability and distribution channels (S4). 
Table 7. The Mann-Whitney U test results for exploring the differences between Poland- and UK-based prosumers' future engagement in knowledge sharing

\begin{tabular}{|c|c|}
\hline \multicolumn{2}{|c|}{ Engagement in knowledge sharing (would like to share) } \\
\hline P1 & 0.000 \\
\hline P2 & 0.000 \\
\hline P3 & 0.000 \\
\hline P4 & 0.000 \\
\hline P5 & 0.000 \\
\hline P6 & 0.000 \\
\hline P7 & 0.000 \\
\hline S1 & 0.000 \\
\hline S2 & 0.000 \\
\hline S3 & 0.642 \\
\hline S4 5 & 0.000 \\
\hline S6 & 0.378 \\
\hline S7 & 0.030 \\
\hline
\end{tabular}

However, the results for service offerings show a slightly different pattern compared to Table 6. As before, significant differences between Poland-based and UK-based prosumers can be reported for advertising (S1), pricing strategy (S2) and service availability (S4). In the case of future prosumer engagement, the p-value also delivers significant results for complaint handling and warranty services (S6), and customer services (S7) but not for promotions, discounts and loans (S3) and ordering process (S5). In summary, the fourth hypothesis is partially supported.

When comparing the results in terms of the current and potential prosumer engagement, there is evidence for a greater prosumer involvement in the future for Poland-based prosumers in terms of BP3, BP4 and BP5, whereas for the UK-based prosumers the results were on average lower for future knowledge sharing in these areas. There are clearly areas where business can refocus the strategic communication efforts to capitalise on the empowered customer and the dynamic customer relationship building activities enabled by social media platform developments integrated with the enterprise strategic developments (Law, Lau, \& Wong, 2003). Furthermore, this can even be interpreted as a necessity for organisations to survive in contestable markets (Rayna \& Striukova, 2015). As contestable markets are characterised by low market entry and exit costs, no occurrence of sunk costs and immediate access of market entrants to technology of the same level as market incumbents (Baumol, 1983), active consumers could become competitors if organisations do not value and embed customer input. As the results presented in this paper have shown, both groups of 
prosumers express a greater desire to share their knowledge with organisations in the future with an even higher tendency for Poland-based versus UK-based prosumers. Therefore, organisations should take this opportunity and provide platforms for their customers to engage in a two-way communication process throughout all business product stages. As the results have shown, a high prosumer engagement already exists in areas where B2C interaction opportunities are in place, such as service delivery and customer service. However, especially in the case of Poland-based prosumers, organisations could benefit from external consumer knowledge during the product development stages and more specifically in the processes of product packing or graphic elements of the product, product functionality and ease and intuitiveness of product use.

As summarised in Table 8, the results revealed partial support for two of the formulated hypotheses ( $\mathrm{H} 2$ and $\mathrm{H} 4)$ and full support for other two hypotheses (H1 and H3).

Table 8. Summary of hypotheses tests

\begin{tabular}{|l|l|}
\hline \multicolumn{1}{|c|}{ Hypotheses } & \multicolumn{1}{|c|}{ Findings } \\
\hline $\begin{array}{l}\text { H1: There is a statistically significant difference between Poland-based and UK-based } \\
\text { prosumers engagement in knowledge sharing in BP2 combined activities }\end{array}$ & $\begin{array}{l}\text { Fully } \\
\text { supported }\end{array}$ \\
\hline $\begin{array}{l}\text { H2: There is a statistically significant difference between Poland-based and UK-based } \\
\text { prosumers engagement in knowledge sharing in BP3, 4 and 5 combined activities }\end{array}$ & $\begin{array}{l}\text { Partially } \\
\text { supported }\end{array}$ \\
\hline $\begin{array}{l}\text { H3: There is a statistically significant difference between Poland-based and UK-based } \\
\text { prosumers future engagement in knowledge sharing in BP2 combined activities }\end{array}$ & $\begin{array}{l}\text { Fully } \\
\text { supported }\end{array}$ \\
\hline $\begin{array}{l}\text { H4: There is a statistically significant difference between Poland-based and UK-based } \\
\text { prosumers future engagement in knowledge sharing in BP3, 4 and 5 combined activities }\end{array}$ & $\begin{array}{l}\text { Partially } \\
\text { supported }\end{array}$ \\
\hline
\end{tabular}

\section{Conclusions}

This work contributes to the research on prosumers engagement in knowledge sharing by:

- addressing the kinds of knowledge that Poland-based prosumers share and are willing to share in the future;

- addressing the kinds of knowledge that UK-based prosumers share and are willing to share in the future in relation to product and services

What are the implications for organisations?

As the results suggest a higher desire for Poland-based prosumers to engage with enterprises in the future, UK-based organisations should consider a more encouraging approach to motivate customers involvement. 
UK businesses can learn from this, in restating their strategy, knowing the different knowledge preferences of Poland-based and UK-based prosumers engagement in the product and service development process with enterprises now and in the future.

\section{Implications for research and practice}

This study can be useful for researchers. They may use this methodology and do similar analyses with different samples in Poland, the UK, and other countries, additionally many comparisons between different groups and countries can be made. Moreover, the methodology constitutes a very comprehensive basis for identifying the kinds of knowledge that can encourage prosumers to engage in knowledge sharing, but researchers may develop, verify and improve this methodology and its implementation. In addition, researchers may use these research findings and employ them in studies of enterprises. Furthermore, for practitioners, the results of this study can be used to target the kinds of knowledge that align closely to the business processes and optimise the decision outputs gained through knowledge sharing. Specifically addressing the following question - How can prosumers be encouraged to knowledge sharing.

The study also has some limitations. The selection of survey respondents needs to be considered in the light of the results, as they indicated that the majority of the respondents were young individuals below 35 years of age in Poland. In this case it is advisable to extend the research study to widen the age participation, and it would be useful to broaden the study to research elderly individuals, such as prosumers above age 50 years.

A second limitation relates to bias, as the original survey was designed in Polish and translated into English there may be some issues to address regarding the technical language which may be viewed as complex or consisting of uncommon words which then affect how the respondents interpret the question. A pilot questionnaire was completed in the UK and questions were amended, and the vertical response scale was used to provide lists of response options as this reduces confusion from respondents. However, translation often results in a language bias that may affect the results. Further research will address the effect of common language where technical jargon can be reworded and sentences rephrased so as to limit the nature of ambiguous questions. 


\section{References}

Aghamirian, B., Dorri, B., \& Aghamirian, B. (2013). Effects of customer knowledge management's eight factors in e-commerce. Management Science and Engineering, 7(4), 1-11. https://doi.org/10.3968/3945

APQC. (2018). Process Classification Framework [online]. Houston: American Productivity and Quality Center. Retrieved January 20, 2017 from http://www.apqc.org/pcf

Baumol, W. J. (1983). Contestable markets: An uprising in the theory of industry structure. American Economic Review, 73(3), 491-496.

Brabham, D. C. (2012). Motivations for participation in a crowdsourcing application to improve public engagement in transit planning. Journal of Applied Communication Research, 40(3), 307-328. https://doi.org/10.1080/00909882.2012.693940

Bylok, F. (2013). Konsumpcja, konsument i społeczeństwo konsumpcyjne we wspótczesnym świecie [Consumption, the consumer and the consumer society in the modern world]. Katowice: Śląsk.

Chesbrough, H. W. (2007). Why companies should have open business models. MIT Sloan Management Review, 48(2). Retrieved from https://sloanreview.mit.edu/ article/why-companies-should-have-open-business-models/

Cui, A. S., \& Wu, F. (2015, March). Utilizing customer knowledge in innovation: Antecedents and impact of customer involvement on new product performance. Journal of the Academy of Marketing Science, 1-23. https://doi.org/10.1007/s11747-015-0433-X

Fine, M. B., Gironda, J., \& Petrescu, M. (2017). Prosumer motivations for electronic word-of-mouth communication behaviors. Journal of Hospitality and Tourism Technology, 8(2), 280-295. https://doi.org/10.1108/JHTT-09-2016-0048

Geri, N., Gafni, R., \& Bengov, P. (2017). Crowdsourcing as a business model: Extrinsic motivations for knowledge sharing in user-generated content websites. Journal of Global Operations and Strategic Sourcing, 10(1), 90-111. https://doi.org/10.1108 /JGOSS-052016-0018

Hernández-Serrano, M. J., Renés-Arellano, P., Graham, G., \& Greenhill, A. (2017). From prosumer to prodesigner: Participatory news consumption. Comunicar, 25(50), 77-87. https://doi.org/10.3916/C50-2017-07

Hinton, P. R., Brownlow, C., McMurray, I., \& Cozens, B. (2004). SPSS explained. London: Routledge.

Law, M., Lau, T., \& Wong, Y. H. (2003). From customer relationship management to customer-managed relationship: Unravelling the paradox with a co-creative perspective. Marketing Intelligence \& Planning, 21(1), 51-60. https://doi.org/10.1108 /02634500310458153

Lusch, R. F., \& Vargo, S. L. (2006). Service-dominant logic: Reactions, reflections, and refinements. Marketing Theory, 6(3), 281-288. https://doi.org/10.1177/1470593106 066781 
Martínez-Cañas, R., Ruiz-Palomino, P., Linuesa-Langreo, J., \& Blázquez-Resino, J. J. (2016). Consumer participation in co-creation: An enlightening model of causes and effects based on ethical values and transcendent motives. Frontiers in Psychology, 7(973), 1-17. https://doi.org/10.3389/fpsyg.2016.00793

Mazurek, M., \& Hilton, M. (2007). Consumerism, solidarity and communism: Consumer protection and the consumer movement in Poland. Journal of Contemporary History, 42(2), 315-343. https://doi.org/10.1177/0022009407075553

O'Brien, C. (2011). The emergence of the social media empowered consumer. Irish Marketing Review, 21(1\&2), 32-40.

Osterwalder, A., \& Pigneur, Y. (2002). An eBusiness model ontology for modeling eBusiness. BLED 2002 Proceedings. 15th Bled Electronic Commerce Conference, Bled, Slovenia.

Osterwalder, A., \& Pigneur, Y. (2013). Business model generation: A handbook for visionaries, game changers and challengers. Oxford: John Wiley and Sons.

Payne, A. F., Storbacka, K., \& Frow, P. (2008). Managing the co-creation of value. Journal of the Academy of Marketing Science, 36(1), 83-96. https://doi.org/10.1007 /s11747-007-0070-0

Planells, A. J. (2015). Video games and the crowdfunding ideology: From the gamer-buyer to the prosumer-investor. Journal of Consumer Culture, 17(3), 620-638. https://doi.org/10.1177/1469540515611200

Porter, M. E. (1985) Competitive advantage. New York: Free Press.

Rayna, T., \& Striukova, L. (2016). Involving consumers: The role of digital technologies in promoting 'prosumption' and user innovation. Journal of the Knowledge Economy, 1-20. https://doi.org/10.1007/s13132-016-0390-8

Ritzer, G., \& Jurgenson, N. (2010). Production, consumption, prosumption: The nature of capitalism in the age of the digital 'prosumer'. Journal of Consumer Culture, 10(1), 13-36. https://doi.org/10.1177/1469540509354673

Song, E.-J., \& Kang, M.-S. (2016). A study on the platform of knowledge integration for customer feedback in B2C service industry. International Journal of Information and Communication Technology, 8(1), 26-36. https://doi.org/10.1504/ ijict.2016. 073637

Taherparvar, N., Esmaeilpour, R., \& Dostar, M. (2014). Customer knowledge management, innovation capability, and business performance: A case study of the banking industry. Journal of Knowledge Management, 3(18). Retrieved May 12, 2014 from http://www.emeraldinsight.com/journals.htm?issn=1367-3270\&volume=18\& issue $=3$

Tapscott, D., \& Williams, A. D. (2006). Wikinomics: How mass collaboration changes everything. New York: Penguin Group.

Toffler, A. (1980). The third wave. New York: Bantam Books. 
Tsai, W., Tsai, M., Li, S., \& Lin, C. (2012). Harmonizing firms' knowledge and strategies with organizational capabilities. Journal of Computer Information Systems, 53(1), 23-32.

Tseng, S.-M. (2016). The effect of knowledge management capability and customer knowledge gaps on corporate performance. Journal of Enterprise Information Management, 29(1), 5171. https://doi.org/10.1108/JEIM-03-2015-0021

Xie, C., Bagozzi, R. P., \& Troye, S. V. (2008). Trying to prosumer: Toward a theory of consumers as co-creators of value. Journal of the Academy of Marketing Science, 36, $109-122$.

Ziemba, E., \& Eisenbardt, M. (2015a). Examining prosumers participation in business processes. Polish Journal of Management Studies, 12(1), 219-229.

Ziemba, E., \& Eisenbardt, M. (2015b). Prosumers' participation in business processes. Online Journal of Applied Knowledge Management, 3(1), 114-127. Retrieved from http://www.iiakm.org/ojakm/articles/2015/volume3_1/OJAKM_Volume3_1pp114127.pdf

Ziemba, E., \& Eisenbardt, M. (2017). Utilization of consumers' knowledge in organizations. In F. Marimon, M. Mas-Machuca, J. Berbegal-Mirabent, \& R. Bastida (Eds.), Proceedings of the 18th European Conference on Knowledge Management ECKM 2017, September 7-8 (Vol. 2, pp. 1084-1093). Barcelona: International University of Catalonia.

Ziemba, E., Eisenbardt, M., \& Mullins, R. (2017). Use of information and communication technologies for knowledge sharing by Polish and UK-based prosumers. In: E. Ziemba (Ed.), Information Technology for Management: New Ideas and Real Solutions (Lecture Notes in Business Information Processing, No. 277; pp. 49-73). Switzerland: Springer. https://doi.org/10.1007/978-3-319-53076-5_4

Ziemba, E., Eisenbardt, M., Mullins, R., \& Grabara, D. (2018). Prosumers knowledge sharing to develop and manage products. Online Journal of Applied Knowledge Management, 6(2), 72-91. https://doi.org/10.36965/OJAKM.2018.6(2)72-91

Ziemba, E., \& Mullins, R. (2016). Identifying more about customers: The phenomenon of the switch to the knowledge exchange. Online Journal of Applied Knowledge Management, 4(1), 165-179. https://doi.org/10.36965/OJAKM.2016.4(1)165-179 